Research Article

\title{
Prediction Model and Experimental Study on Braking Distance under Emergency Braking with Heavy Load of Escalator
}

\author{
Zhongxing Li $\mathbb{D}^{1}{ }^{1}$ Haixia Ma $\mathbb{D}^{2}{ }^{2}$ Peng Xu $\mathbb{D},{ }^{3}$ Qifeng Peng, ${ }^{1}$ Guojian Huang, \\ and Yingjie Liu ${ }^{1}$ \\ ${ }^{1}$ Guangzhou Academy of Special Equipment Inspection \& Testing, Guangzhou 510180, China \\ ${ }^{2}$ Guangzhou College of South China University of Technology, Guangzhou 510800, China \\ ${ }^{3}$ MOE Key Laboratory of Disaster Forecast and Control in Engineering, School of Mechanics and Construction Engineering, \\ Jinan University, Guangzhou 510632, China
}

Correspondence should be addressed to Haixia Ma; mahx@gcu.edu.cn and Peng Xu; 325802168@qq.com

Received 16 July 2020; Revised 8 August 2020; Accepted 17 August 2020; Published 2 September 2020

Academic Editor: Guoqiang Wang

Copyright ( 2020 Zhongxing Li et al. This is an open access article distributed under the Creative Commons Attribution License, which permits unrestricted use, distribution, and reproduction in any medium, provided the original work is properly cited.

In order to study the relationship between the braking distance and the load of escalator and realize the prediction of the rated load braking distance with a little load, the method of combining theoretical analysis and experimental research is used. First, the dynamic characteristics of the escalator during emergency braking are analyzed, and the prediction model of the braking distance of the escalator under different loads is derived based on the law of conservation of energy. Furthermore, the influence coefficients under different loads were determined through experimental studies, the model was revised, and the concept of equivalent no-load kinetic energy (ENKE) was proposed. The research shows that the braking distance of the escalator increases nonlinearly with the increase in load. When the no-load braking distance and the $25 \%$ rated load braking distance change greatly, the braking distance increases faster as the load increases; the escalators with large brake force have a small ENKE and are easy to stop. Otherwise, it is difficult to stop. The test results show that the comparison between the predicted value of the prediction model and the measured value has a maximum error of $2.7 \%$, and the maximum error at rated load is only $2.0 \%$, which fully meets the needs of engineering measurement. And the prediction method reduces test costs, enhances test security, and improves test coverage.

\section{Introduction}

As an important means of transportation in modern buildings, escalator greatly saves physical strength and time and improves traffic efficiency. As a kind of elevator, the escalator is used to transport passengers up or down in an oblique way. It has cyclic steps which are characterized by continuous operation. Compared with the vertical elevator, it has a greater transport capacity and is widely used in airports, shopping malls, stations, and other places with large passenger flow. In recent years, with the rapid development of economy, the number of elevators in China has increased rapidly, especially in the coastal areas. According to the market supervision administration of Guangdong Province website [1], by the end of 2019, the number of special equipment in Guangdong Province was 1.6356 million, 7.33\% more than in 2018, 40800 boilers, 399700 pressure vessels, 853200 sets of elevator, 193500 sets of hoisting machinery, 146200 special motor vehicles, 24 passenger ropeways, and large-scale amusement equipment 2160 units (sets), as shown in Figure 1.

Due to the large amount and high risk, accidents of special equipment occur from time to time. In 2019, there were 15 special equipment accidents in Guangdong Province, including 9 elevator accidents, accounting for $60 \%$. Figure 2 shows the accidents of special equipment in Guangdong Province in 2019. It can be seen that the elevator is not only a large number but also a special equipment with a high incidence of accidents.

Guangdong Provincial government attaches great importance to the safety of special equipment. With the contribution of technical personnel to safety technology, the 


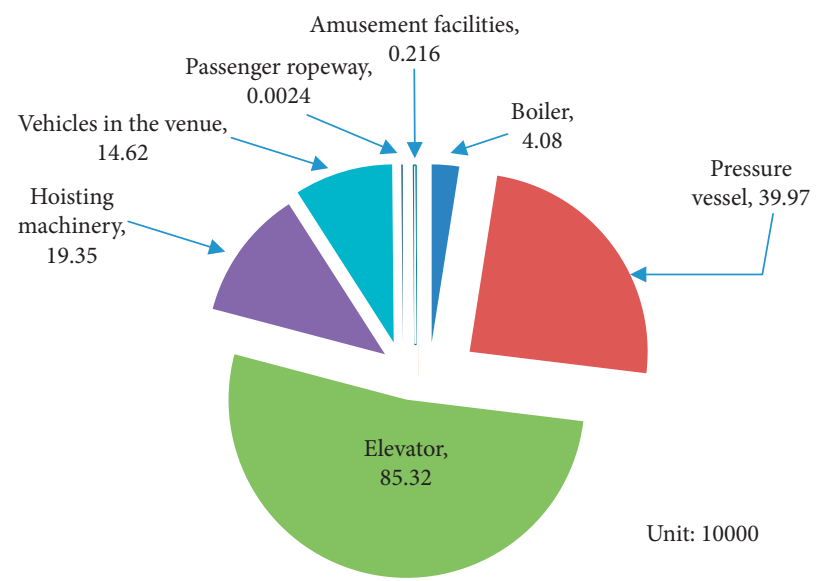

FIgURe 1: Proportion of special equipment in Guangdong Province in 2019.

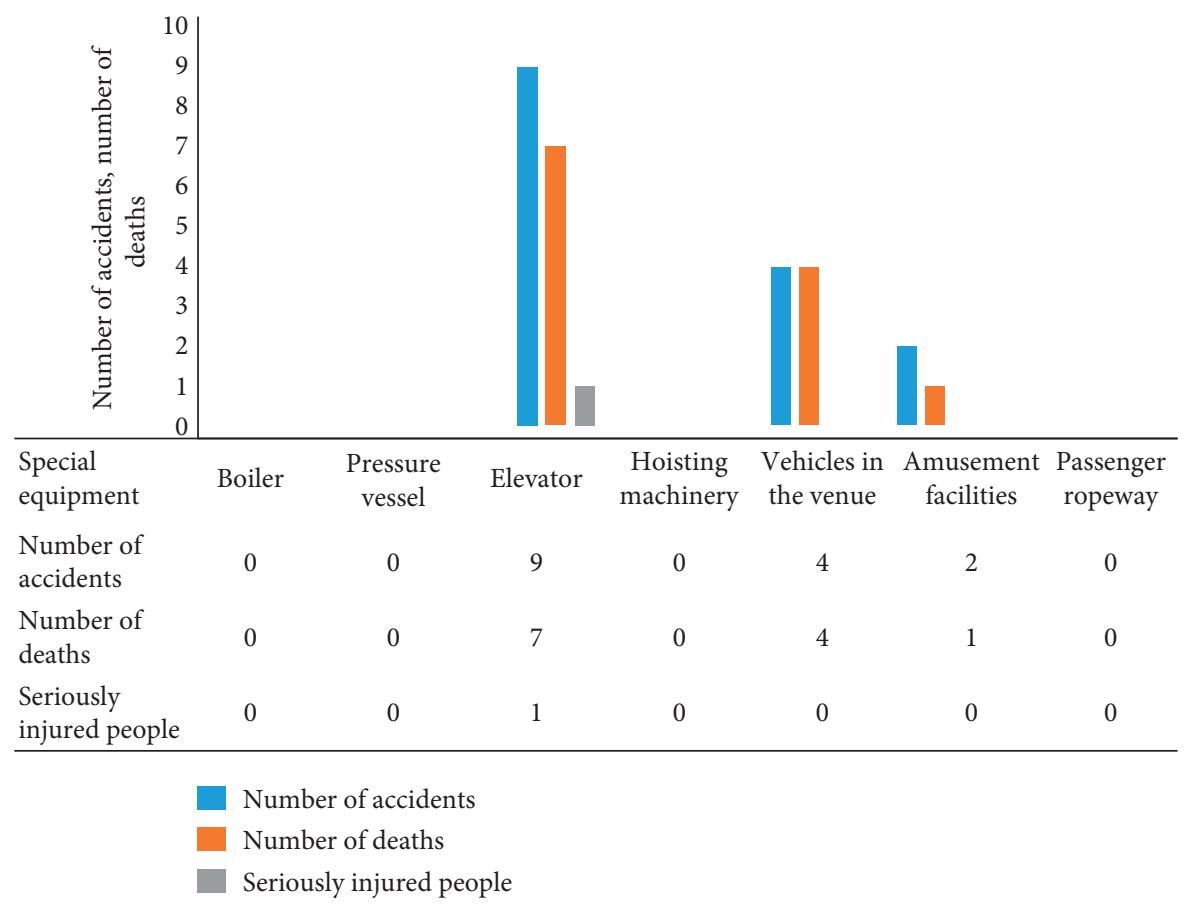

Figure 2: Statistics of special equipment accidents in Guangdong Province in 2019.

deaths number of 10,000 special equipments in Guangdong Province has been decreasing year by year. However, due to the large base, the safety situation is still grim. Figure 3 shows the trend of accidents per 10,000 devices special equipment in Guangdong Province.

As a special equipment, the safety and reliability of escalators have always been the focus of managers and technicians [2-6]. Most escalator accidents occur in crowded public places, causing great personal injury and social impact [7-11]. Therefore, how to prevent accidents and reduce the loss and social impact brought by accidents has been the research direction of scholars in the industry $[10,12-14]$.

As an important part of escalator safety protection, the brake is used to quickly stop the escalator in the event of an emergency and protect the personal safety to the greatest extent. The principle of the brake is shown in Figure 4. The quality of the brake's performance directly affects the safety level of escalators [15-17]. Therefore, in order to improve the safety of escalator brake, domestic and foreign scholars have done a lot of research [18-20].

As an important indicator of brake performance, braking distance is a necessary test item for inspection and maintenance $[21,22]$. GB16899-2011 5.4.2.1 has clearly stipulated the range of braking distance under different rated speeds and takes the detection items of braking distance into one of the items of escalator safety detection [23]. Table 1 shows the standard values of the braking distances of escalators at different nominal speeds.

In Table 1, the minimum braking distance is the limit value with no load, while the maximum braking distance is the limit value with rated load. The traditional rated load test 


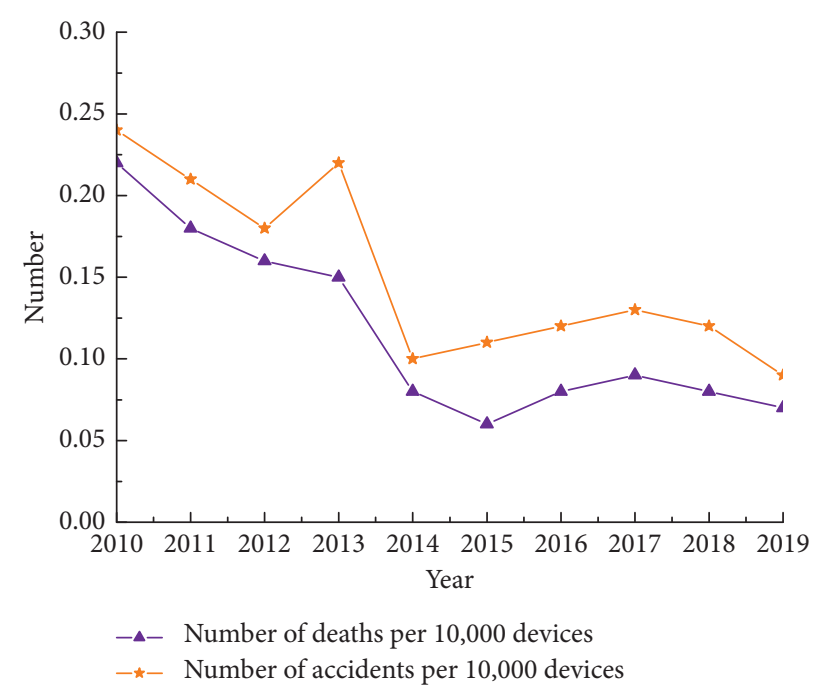

FIgURE 3: The trend of accidents of special equipment in Guangdong Province.

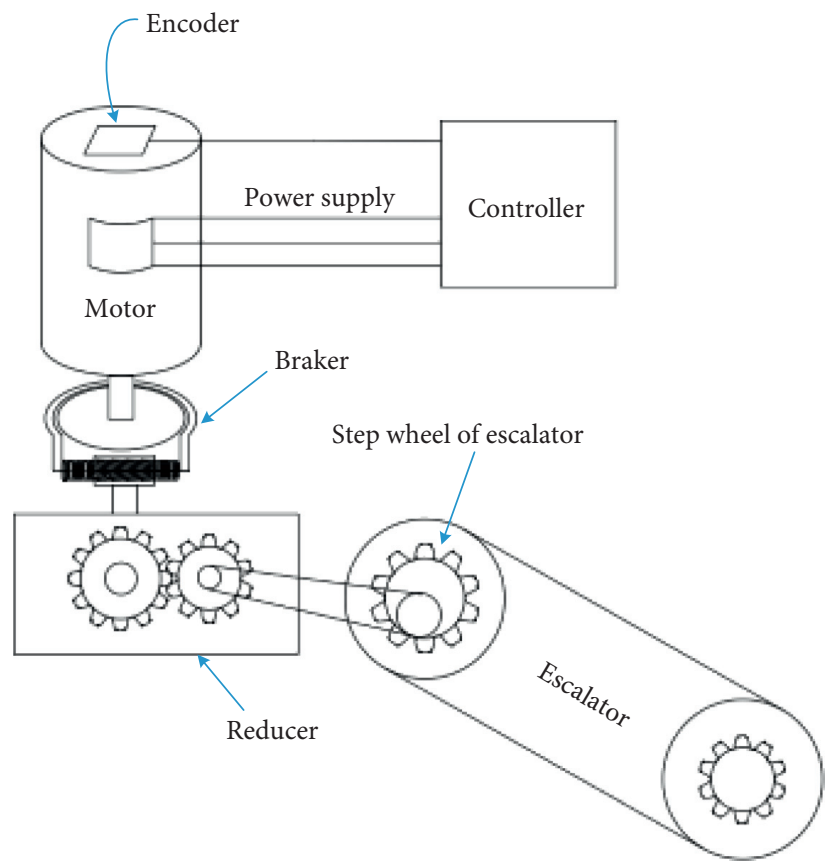

FIgURE 4: Structure principle of brake.

TABLE 1: Escalator braking distance range at different nominal speeds.

\begin{tabular}{lcc}
\hline Nominal speeds $V_{0}(\mathrm{~m} / \mathrm{s})$ & Minimum braking distance $S_{\min }(\mathrm{m})$ & Maximum braking distance $S_{\text {max }}(\mathrm{m})$ \\
\hline 0.5 & 0.2 & $1.0^{\mathrm{a}}$ \\
0.65 & 0.3 & $1.3^{\mathrm{a}}$ \\
0.75 & 0.4 & $1.5^{\mathrm{a}}$ \\
\hline
\end{tabular}

${ }^{\mathrm{a} E x c l u d i n g}$ endpoint values.

of the braking distance of escalators is mainly carried out by loading. When the escalator comes to an emergency stop under the rated load, the braking distance is measured to judge the braking performance of the brake. Rated load is required during the experiment. Due to the need to reserve the braking distance, the load will generally be concentrated on the upper part of the escalator, which can cause excessive load concentration. There are two problems in the load test: first, it is difficult to carry the weight that is required by the test, and the cost of handling is high; second, the brake 
performance of the escalator with a long service life may not meet the requirements of the rated load test. And the escalator cannot be stopped reliably under rated load, which is a great potential safety hazard. The loading test situation is shown in Figure 5(a). Especially, in some shopping malls, there is a human activity space under the escalator, as shown in Figure 5(b). Once the brake is unable to stop the escalator reliably at rated load, in some cases, the escalator is damaged, and in other cases, personal injury or death will be caused.

Consider the high cost and risk of rated load test of braking distance. At present, for the annual inspection and maintenance of escalators, there is no rated load test, only the measurement of no-load braking distance. However, the actual situation is that escalators in China often operate under heavy load, as shown in Figure 5(c). This brings great safety hazard to passengers. In order to reduce the cost of rated load test and reduce the test risk, it is particularly important to study the equivalent test method under the condition of light load. By establishing the relationship model between the braking distance and load, the braking distance of escalator under heavy load will be predicted.

Some scholars have studied the relationship between the test of the braking distance and safety. Wang and Lu proposed a method for calculating the braking capacity of escalators and moving walkways. The braking torque is selected through braking deceleration and then proofread stop distance [24]. Based on the design requirements of the escalator braking system, Pan studied the influencing factors of the braking distance and put forward proposed improvements to the inspection requirements of the braking distance [25]. Hu established a new method for calculating the mathematical model of the escalator braking distance and used this method to calculate some structural parameters of the escalator [26]. Liu analyzed the calculation of the braking distance of the escalator and established the relevant calculation formula [27]. Park and Gschwendtner proposed an efficient multibody dynamics simulation modeling approach. The approach also covers a comprehensive simulation modeling of drive machine with gearbox, main drive chain band, operational brake system, and auxiliary brake system to evaluate the escalator brake performance at the system level [21]. The work of the researchers provided an important reference for the study of the braking distance of escalators. However, most of the research on the braking distance of escalators is carried out from the aspects of checking and influencing factors, and there are few studies on how to predict the braking distance under various loads without loading or adding light load. In view of this, this paper studies the law of movement in the process of escalator operation, analyzes the energy change during the escalator braking process, analyzes and summarizes a large number of test data, and puts forward a method for braking distance prediction.

In this paper, the braking distance prediction model of the escalator under heavy load is obtained by light load. The method can reduce the test cost and risk, increase the coverage of the braking distance test of rated load, and improve the safety of the escalator. The structure of the paper is as follows: Section 2 is the theoretical analysis, starting from the general equation of mechanical motion, analyzes the law of the movement of the escalator, and constructs the equivalent dynamic model of the escalator system. And the relationship between the braking distance and the load is formed. Section 3 establishes the escalator braking distance prediction model. Through the analysis of the law of energy change in the braking process and according to the conservation of energy, a simpler relationship between the braking distance and the load is deduced and tested. Section 4 is the improved prediction model of the braking distance of the escalator. The prediction model derived in the Section 3 is improved, and the calculation method of the influence coefficient is given. Section 5 is the calculation results of the improved model. Three escalators with different parameters are tested, and compared with the predicted data, the results are basically consistent to meet the needs of engineering measurement. In the fifth section, the test results of three escalators are analyzed. The sixth section is the conclusion.

\section{Theoretical Analysis}

2.1. General Equations of Mechanical Motion. For a mechanical system composed of moving components, the acting force on the component $i$ is $F_{i}$, the torque is $M_{i}$, the velocity of the point of force is $v_{i}$, the angular velocity of the component is $\omega_{i}$, the velocity of the center of mass is $v_{s i}$, and the moment of inertia of the center of mass is $J_{s i}$, then there is

$$
d\left[\sum_{i=1}^{n} \frac{m_{i} v_{s i}^{2}}{2}+\frac{j_{s i} \omega_{i}^{2}}{2}\right]=d\left[\sum_{i=1}^{n}\left(F_{i} v_{i} \cos \alpha_{i} \pm M_{i} \omega_{i}\right)\right] \cdot \mathrm{d} t,
$$

where $\alpha_{i}$ is the angle between force and velocity, plus or minus sign depends on the direction of the torque $M_{i}$ acting on the component and the angular velocity $\omega_{i}$ of the component. When they are the same, "+" is taken, and when they are opposite, "-" is taken.

Equation (1) shows that, for complex systems, there are many components and it is difficult to solve. However, single-degree-of-freedom mechanical systems can be simplified by equivalent.

2.2. Equivalent Dynamic Model of Escalator System. According to the mechanical principle, the single-degree-offreedom mechanism can be reduced to an equivalent component with equivalent mass or equivalent rotational inertia [28]. At this time, the motion law of the equivalent component is the same as that in the mechanism. The condition of the equivalent rotational inertia is that the kinetic energy of the equivalent component with the equivalent rotational inertia (mass) is equal to the kinetic energy of the original mechanical system. Due to the kinetic energy theorem, during mechanical operation, the elemental work done $\mathrm{dw}$ by all external forces in any time interval $\mathrm{d} t$ should be equal to the increase in $\mathrm{d} E$ in kinetic energy of the mechanical system: 


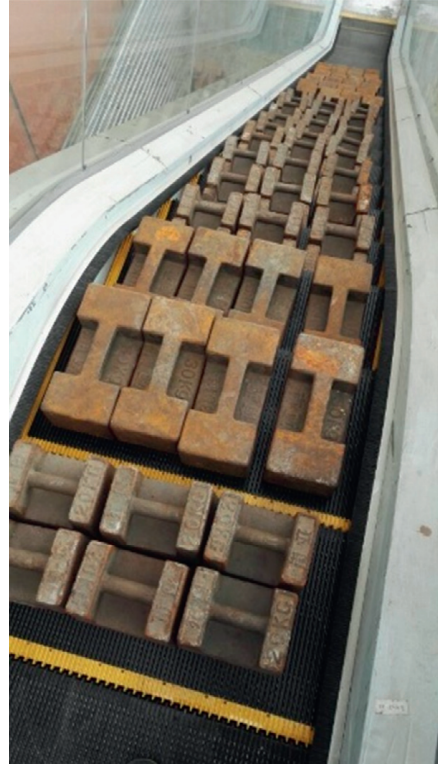

(a)

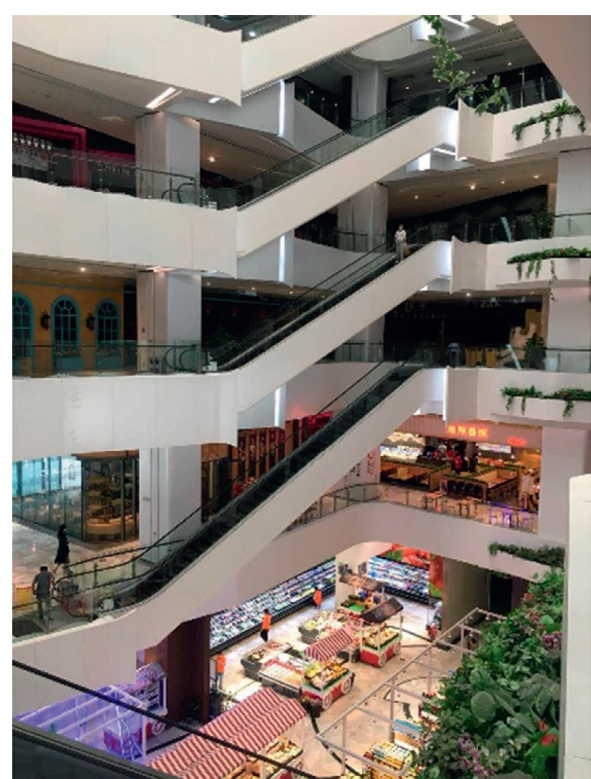

(b)

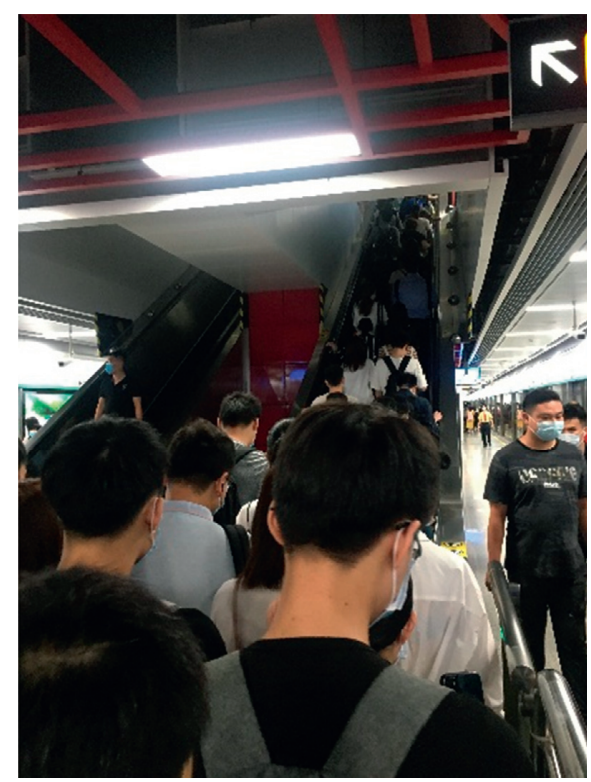

(c)

FIGURE 5: Escalator status: (a) escalator loading test; (b) escalator of mall; (c) status of escalator operation.

$$
\mathrm{dw}=\mathrm{d} E .
$$

For the escalator system shown in Figure 6, let the angular speed of the step sprocket be $\omega_{1}$, the mass is $m_{1}$, the moment of inertia is $J_{1}$, the mass of all the steps is $m_{2}$, the speed of the step is $v_{2}$, the load mass is $m_{3}$, and the speed of load is $v_{3}$.

When running with no load, there is

$$
\begin{aligned}
& \mathrm{d} E=d\left(\frac{J_{1} \omega_{1}^{2}}{2}+\frac{m_{2} v_{2}^{2}}{2}\right), \\
& \mathrm{d} \mathrm{w}=M_{1} \omega_{1} \cdot \mathrm{d} t .
\end{aligned}
$$

From equation (2),

$$
d\left\{\frac{\omega_{1}^{2}}{2}\left[J_{1}+m_{2}\left(\frac{v_{2}}{\omega_{1}}\right)^{2}\right]\right\}=M_{1} \omega_{1} \cdot \mathrm{d} t .
$$

Make $J_{e 0}=J_{1}+m_{2} \cdot\left(v_{2} / \omega_{1}\right)^{2}$ and $M_{e 0}=M_{1}$, where $J_{e 0}$ is the moment of inertia equivalent to the step sprocket, $M_{e 0}$ is the equivalent torque of the step sprocket, and $M_{1}$ is the electromagnetic torque converted to the step sprocket.

When running down with rated load, there is

$$
\begin{aligned}
& \mathrm{d} E=d\left(\frac{J_{1} \omega_{1}^{2}}{2}+\frac{m_{2} v_{2}^{2}}{2}+\frac{m_{3} v_{3}^{2}}{2}\right), \\
& \mathrm{dw}=\left(m_{3} g \sin \alpha \cdot v_{3}-M_{1} \omega_{1}\right) \cdot \mathrm{d} t .
\end{aligned}
$$

Due to $v_{2}=v_{3}=v$,

$$
d\left\{\frac{\omega_{1}^{2}}{2}\left[J_{1}+m_{2}\left(\frac{v}{\omega_{1}}\right)^{2}+m_{3}\left(\frac{v}{\omega_{1}}\right)^{2}\right]\right\}=\omega_{1}\left[\frac{m_{3} g \sin \alpha \cdot v}{\omega_{1}} M_{1}\right] \mathrm{d} t .
$$

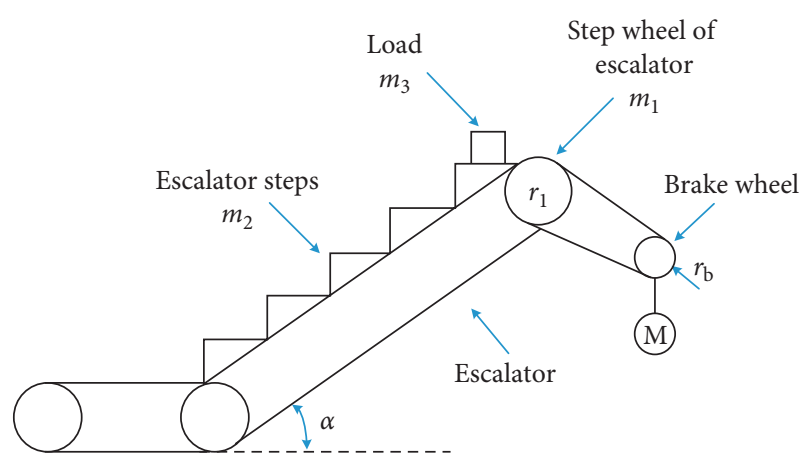

Figure 6: The motion model of escalator.

Make $J_{e 1}=J_{1}+\left(m_{2}+m_{3}\right) \cdot\left(v / \omega_{1}\right)^{2}$ and $M_{e 1}=\left(\left(m_{3} g\right.\right.$ $\left.\left.\sin \alpha \cdot v / \omega_{1}\right)-M_{1}\right)$, where $J_{e 1}$ is the equivalent moment of inertia of the step sprocket and $M_{e 1}$ is the equivalent torque of the step sprocket.

The equivalent moment of inertia converted to the brake wheel is

$$
J_{e 1}^{\prime}=J_{e 1} \cdot\left(\frac{n_{1}}{n_{b}}\right)^{2} \cdot \eta
$$

In equation (7), $n_{1}$ is the speed of the step sprocket, $\mathrm{m} / \mathrm{s}$; $n_{b}$ is the speed of the brake wheel, $\mathrm{m} / \mathrm{s}$; and $\eta$ is the transmission efficiency.

The torque converted to the brake wheel is

$$
M_{e 1}^{\prime}=\frac{M_{e 1}}{\eta} \cdot \frac{n_{1}}{n_{b}}
$$

On applying brake to the escalator, the braking distance 


$$
S=\frac{v^{2}}{2 a}
$$

where $v$ is the escalator running speed, $\mathrm{m} / \mathrm{s}$, and $a$ is the deceleration, $\mathrm{m} / \mathrm{s}^{2}$.

The angular deceleration converted to the brake wheel is

$$
\varepsilon_{b}=\frac{a}{R_{1}} \cdot \frac{n_{1}}{n_{b}},
$$

where $R_{1}$ is the radius of the step sprocket, $m$.

Since the braking torque of the brake is constant, set to $M_{b}$, there is

$$
\varepsilon_{b}=\frac{M_{b}-M_{e 1}^{\prime}}{J_{e 1}^{\prime}}
$$

From equations (9)-(11),

$$
\begin{aligned}
S & =\frac{v^{2} \cdot n_{1} \cdot J_{e 1}^{\prime}}{2 R_{1} n_{b}\left(M_{b}-M_{e 1}^{\prime}\right)} \\
& =\frac{v^{2} \cdot n_{1} \cdot\left[J_{1}+\left(m_{2}+m_{3}\right) \cdot\left(v / \omega_{1}\right)^{2}\right] \cdot\left(n_{1} / n_{b}\right)^{2}}{2 R_{1} n_{b}\left[M_{b}-\left(\left(m_{3} g \sin \alpha \cdot v / \omega_{1}\right)-M_{1}\right) \cdot\left(n_{1} / n_{b}\right)\right]} .
\end{aligned}
$$

It can be seen from equation (12) that when applying brake, the motor power is disconnected, and the electromagnetic torque is zero. The braking distance is related to the mass of the load. As the load increases, the numerator increases, the denominator decreases, and the braking distance increases rapidly. Although the values such as moment of inertia and braking torque can be measured, they involve many and complicated parameters. For the installation site of the escalator, even some parameters cannot be obtained. Therefore, it is very difficult to calculate the braking distance with rated load and can only be measured by loading. This article attempts to analyze the relationship between the braking distance and the load from another angle to achieve the purpose of predicting the braking distance with rated load. By the analysis of energy changes during braking, a mathematical model of braking distance and load is established based on energy conservation, and the influence of some intermediate details is equivalent to a coefficient. Finally, the braking distance prediction of the escalator with rated load and various loads is realized.

\section{Prediction Model of Braking Distance of Escalator}

3.1. Energy Analysis of Escalator Braking Process. The brakes of escalator products are currently mechanical; that is, the brake system relies on the friction torque to stop the system that drives the main engine to run. Applying brake to an escalator or moving walkway running at a rated speed is the mechanics to consume all the inertial energies of moving parts of the stairway and the load through the frictional resistance between the brake wheel and the brake shoe and stop it within a distance. Taking an escalator as an example, the energy change during braking is shown in Figure 7.

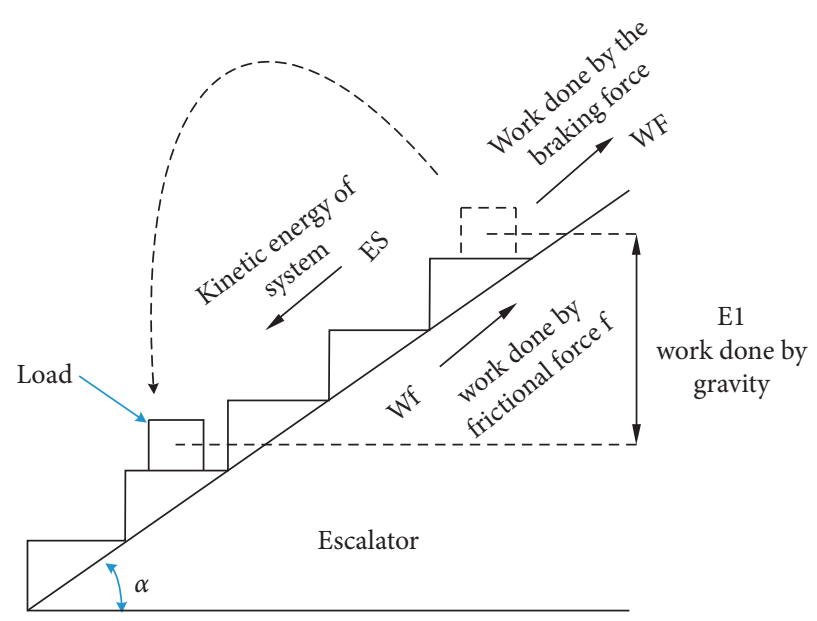

FIgURE 7: Energy changes during escalator braking.

In Figure 7, the energy of the escalator movement process includes the following: the kinetic energy of the system (including all linear moving parts and rotating moving parts), the work done by the friction of the system, the work done by the gravity of the load, and the work done by the braking force during braking.

\subsection{Mathematical Model of Relationship between Braking} Distance and Load. The escalator is driven by the motor through the gears to drive the steps and the handrails to make a circular movement. When the fault occurs or the safety switch is activated, the safety circuit is disconnected and the motor loses its power source. At this time, the brake coil is deenergized, and the brake decelerates the brake wheel to stop. During braking, the kinetic energy and potential energy are reduced, the braking force does work, and finally reaches a state of equilibrium.

According to the law of conservation of energy, the sum of the work done by the braking force and the friction force is equal to the reduction of the kinetic energy of the system and the reduction of the potential energy of load. Then,

$$
W_{\mathrm{F}}+W_{\mathrm{f}}=E_{\mathrm{S}}+E_{\mathrm{l}} \text {, }
$$

where $W_{\mathrm{F}}$ is the work of the braking force, $W_{\mathrm{f}}$ is the work of the friction, $E_{\mathrm{S}}$ is the kinetic energy of the system, and $E_{1}$ is the work of gravity of the load.

In order to simplify the calculation, an equivalent method is adopted. Simplify the influence of friction and efficiency into an influence coefficient $\lambda$, so as to achieve the equivalent purpose. The core idea is to use the braking force to do work to consume the energy of the system. Two cases of no load and rated load are taken to be considered. Assume that the no load and the rated load have the same influence coefficient. When the escalator is running without load, the work done by the braking force is equal to the reduction of kinetic energy multiplied by the influence factor:

$$
F S_{0}=\lambda E_{0} .
$$

When the escalator is loaded with a mass of $m_{1}$, there are 


$$
\mathrm{FS}_{1}=\lambda\left(\frac{1}{2} m_{1} v^{2}+E_{0}+m_{1} g S_{1} \sin \alpha\right),
$$

where $F$ is the braking force equivalent to the step chain; kinetic energy with no load is $E_{0}^{\prime}=(1 / 2) m v^{2}+(1 / 2) J \omega^{2} ; m_{1}$ is the load mass; $S_{1}$ is the braking distance corresponding to $m_{1} ; S_{0}$ is the braking distance with no load; $m$ is the mass of linear moving parts with no load; $J$ is the rotational inertia of the rotating parts with no load; $E_{0}$ is the ENKE related to $E_{0}^{\prime}$; that is, the energy consumed in addition to the load energy; and $\lambda$ is the influence coefficient, which is affected by unknown parameters such as friction and transmission efficiency.

From equations (1) and (2), the relationship between the braking distance and the load is as follows:

$$
S_{1}=\frac{(1 / 2) m_{1} v^{2} S_{0}+E_{0} S_{0}}{E_{0}-m_{1} g \sin \alpha \cdot S_{0}}
$$

Equations (16) and (12) show the relationship between the braking distance and the load from two different angles. From the comparison between equations (16) and (12), it can be seen that they are similar in the following aspects: when the load increases, the numerator increases and the denominator decreases; the braking distance increases with the increase in load, and the closer to the rated load, the greater the increase in braking distance. However, the parameters to be measured in equation (16) are significantly less than those in equation (12), which shows that using equation (16) to predict the braking distance is more simple and convenient.

3.3. Test and Verification. The braking distance of the escalator under different loads can be obtained by equation (16). Although the ENKE in the model is a fixed value, it is related to many factors, and it is difficult to calculate accurately. In order to simplify the calculation, this paper proposed the back derivation method to obtain the ENKE. And then, substitute it into equation (16) to obtain the braking distance of the corresponding load. This not only avoids the high cost but also avoids the safety hazards of rated load testing.

Principle of back derivation method: for equation (16), braking distance with no load can be measured experimentally. $v, g$, and $\alpha$ are all fixed values, $m_{1}$ is the mass of the load, and $E_{0}$ is the ENKE, which is a constant related to the braking force. According to the analysis, when the load mass $m_{1}$ is given, the braking distance $S_{1}$ can be obtained. Conversely, by testing the value of $S_{1}$ under load $m_{1}$, the magnitude of the ENKE $E_{0}$ can be calculated. If two braking distance tests are conducted under no-load and few-load conditions, respectively, the ENKE under the current conditions can be obtained by equation (16).

After calculating the ENKE by the back derivation method, only the braking distance $S_{1}$ and the load $m_{1}$ to be loaded are unknown in equation (16). This means that, as long as the load value is given, the braking distance under any load can be obtained. Take 3 different escalators as examples to verify equation (16).
The infrared-based ranging sensor tester is used for the braking distance test of escalator, which is designed independently. The parameters of the instrument are shown in Table 2.

3.3.1. Test Method. Place the instrument on the step, reserve enough braking distance, and start the escalator operation; when the escalator reaches a uniform speed, press the emergency stop button and test the relative distance of the instrument in real time during the braking process. Once the emergency stop signal is detected, the relative distance is recorded once. After the escalator stops, the relative distance is recorded again. The distance between the two measured values is the escalator braking distance. The test site is shown in Figure 8.

Figure $8(\mathrm{a})$ is the braking distance test when there is no load, and Figure $8(\mathrm{~b})$ is the braking distance test when it is rated load.

The parameters of the three tested escalators are shown in Table 3.

3.4. Verification and Analysis. The test of the three escalators was carried out using the test method of braking distance in Section 3.3. The braking distance of the escalators was measured under the conditions of no load and $25 \%, 50 \%$, $75 \%$, and $100 \%$ rated load, respectively. The measured results of the braking distance when there were different loads are shown in Table 4.

As can be seen from Table 4, for the escalator 1 , when the load is $0 \mathrm{~kg}, 450 \mathrm{~kg}$, and $1800 \mathrm{~kg}$, the measured braking distance is $0.3 \mathrm{~m}, 0.38 \mathrm{~m}$, and $0.73 \mathrm{~m}$, respectively. As the load increases, the braking distance increases, and when the load exceeds $50 \%$ of the rated load, the increase in braking distance increases significantly, which basically increases exponentially. For escalators 2 and 3, the same results as escalator 1 are obtained.

Equation (16) considers the ENKE to be a constant value. To verify, the back derivation method is used. Take escalator 1 as an example. Substitute the corresponding braking distance at $0 \mathrm{~kg}$ and at $450 \mathrm{~kg}$ into equation (16). The corresponding ENKE is calculated as $3353.0625 \mathrm{~J}$. In the same way, the braking distances corresponding to $0 \mathrm{~kg}$ and other loads are substituted into equation (16), and the ENKE corresponding to the various loads calculated is $4194 \mathrm{~J}$, $4291.553571 \mathrm{~J}$, and $4649.023256 \mathrm{~J}$. Similarly, the calculation results of escalators 2 and 3 are shown in Table 4 .

It can be seen from the results in Table 4 that the calculated ENKE is inconsistent at different loads. As the load increases, the calculation result of the ENKE also increases. From 25\% to 50\% rated load stage, the ENKE increases faster; from $50 \%$ to $75 \%$ rated load stage, the ENKE increases slowly; and from $75 \%$ to $100 \%$ rated load stage, the ENKE increase rate increases again.

Through theoretical analysis, the ENKE proposed in this paper is related to the braking force. For an escalator, under the condition of a certain braking torque, the ENKE will not change. Then, the corresponding ENKE should be a certain value. However, from the calculation results of the no-load 
TABle 2: Parameters of the instrument.

\begin{tabular}{lccc}
\hline Sampling frequency & $25 \mathrm{~Hz}$ & Resolution & $0.1 \mathrm{~mm}$ \\
\hline Measuring range & $0.1 \sim 100 \mathrm{~m}$ & Transmission interface & Bluetooth \\
Measurement accuracy & $\pm 3 \mathrm{~mm}$ & Operating temperature & $-10 \sim+50^{\circ} \mathrm{C}$ \\
\hline
\end{tabular}

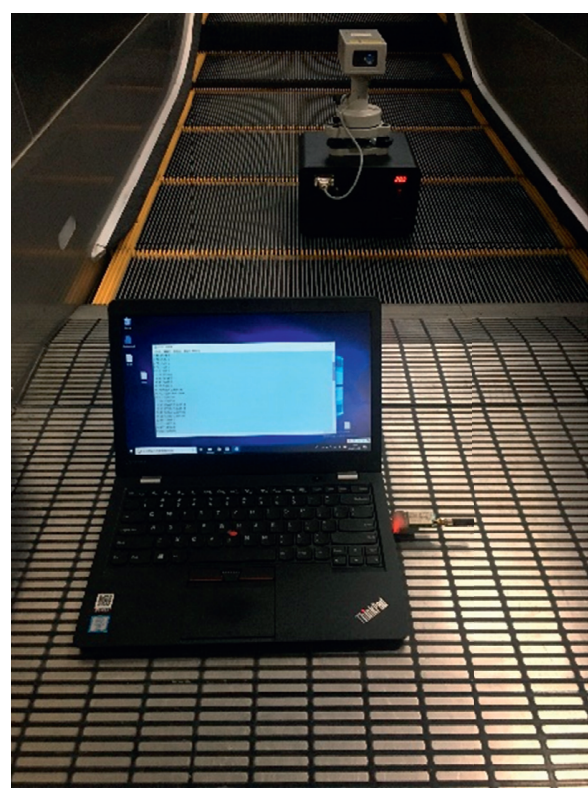

(a)

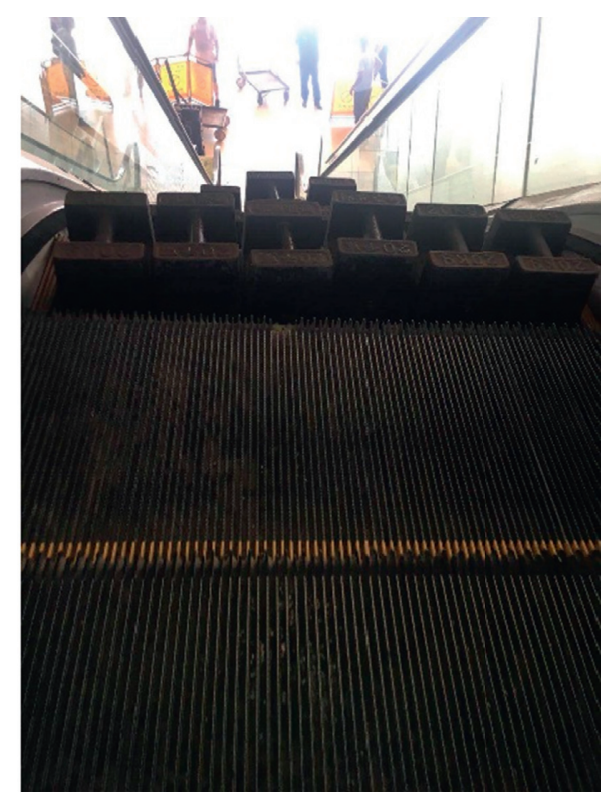

(b)

FIGURE 8: Braking distance test: (a) with no load; (b) with load.

TABLE 3: Parameters of tested escalators.

\begin{tabular}{lccc}
\hline Parameters & Escalator 1 & Escalator 2 & Escalator 3 \\
\hline Nominal speed & $0.5 \mathrm{~m} / \mathrm{s}$ & $0.5 \mathrm{~m} / \mathrm{s}$ & $0.5 \mathrm{~m} / \mathrm{s}$ \\
Tilt angle & $35^{\circ}$ & $35^{\circ}$ & $35^{\circ}$ \\
Lifting height & $4.2 \mathrm{~m}$ & $5.3 \mathrm{~m}$ & $4.8 \mathrm{~m}$ \\
Nominal width & $1000 \mathrm{~mm}$ & $1000 \mathrm{~mm}$ & $1000 \mathrm{~mm}$ \\
Rated load & $1800 \mathrm{~kg}$ & $2760 \mathrm{~kg}$ & $2400 \mathrm{~kg}$ \\
Power & $7.5 \mathrm{kw}$ & $11 \mathrm{kw}$ & $7.5 \mathrm{kw}$ \\
\hline
\end{tabular}

equivalent kinetic energy in Table 4, it can be seen that the ENKE becomes larger with the increase in the load. That is to say, the energy needs to be consumed by the brake in addition to the energy of the load itself, and the increased energy of the ENKE is noticed. It is caused by an increase in load. This is inconsistent with theoretical analysis. The analysis shows that, as the load increases, the friction and efficiency of the escalator system will change, so the impact coefficient of this model will also change with the increase in the load. The next section will improve the model.

\section{Improved Model}

4.1. Modification of the Model. According to the test results and theoretical analysis in the previous section, the calculated ENKE is not a constant but increases with the increase in the load. The analysis shows that, due to the existence of factors such as meshing and friction between the gears, the rated conversion efficiency of the work done by the braking force is deviated. The efficiency of the escalator in no-load and loading operation is different. This shows that the coefficients in equations (14) and (15) are not a constant value but change as the load increases.

So, equation (14) is amended as follows when no load:

$$
\mathrm{FS}_{0}=k_{0} E_{0} \text {. }
$$

Equation (15) is amended as follows when loading:

$$
\mathrm{FS}_{1}=k_{1}\left(\frac{1}{2} m_{1} v^{2}+E_{0}+m_{1} g S_{1} \sin \alpha\right)
$$

Kinetic energy with no load is as follows:

$$
E_{0}^{\prime}=\frac{1}{2} m v^{2}+\frac{1}{2} J \omega^{2} .
$$

Among them, $k_{0}$ is the influence coefficient with no load, and $k_{1}$ is the influence coefficient with loading, which varies with the load. $E_{0}$ is the ENKE, which is related to $E_{0}^{\prime}$, that is, the energy consumed in addition to the load energy.

From equations (17) and (18), the expression of the baking distance with load $m_{1}$ is 
TABLE 4: Test and calculation results of three escalators.

\begin{tabular}{|c|c|c|c|c|c|c|}
\hline \multirow{2}{*}{ Tested escalator } & & \multicolumn{5}{|c|}{ Load percentage (\%) } \\
\hline & & 0 & 25 & 50 & 75 & 100 \\
\hline Escalator 1 (rated load $1800 \mathrm{~kg}$ ) & $\begin{array}{l}\text { Test result of braking distance }(\mathrm{m}) \\
\text { Calculation result of ENKE }(\mathrm{J})\end{array}$ & $\begin{array}{l}0.3 \\
-\end{array}$ & $\begin{array}{c}0.38 \\
3353.06 \\
\end{array}$ & $\begin{array}{c}0.45 \\
4194.00 \\
\end{array}$ & $\begin{array}{c}0.58 \\
4291.55 \\
\end{array}$ & $\begin{array}{c}0.73 \\
4649.02 \\
\end{array}$ \\
\hline Escalator 2 (rated load $2760 \mathrm{~kg}$ ) & $\begin{array}{l}\text { Test result of braking distance }(\mathrm{m}) \\
\text { Calculation result of ENKE }(\mathrm{J})\end{array}$ & $\begin{array}{c}0.34 \\
-\end{array}$ & $\begin{array}{c}0.44 \\
6059.34 \\
\end{array}$ & $\begin{array}{c}0.54 \\
7369.81\end{array}$ & $\begin{array}{c}0.72 \\
7680.53\end{array}$ & $\begin{array}{c}0.92 \\
8305.68\end{array}$ \\
\hline Escalator 3 (rated load $2400 \mathrm{~kg}$ ) & $\begin{array}{l}\text { Test result of braking distance }(\mathrm{m}) \\
\text { Calculation result of ENKE }(\mathrm{J})\end{array}$ & $\begin{array}{c}0.19 \\
-\end{array}$ & $\begin{array}{c}0.23 \\
4062.84\end{array}$ & $\begin{array}{c}0.26 \\
5195.78\end{array}$ & $\begin{array}{c}0.3 \\
5662.83\end{array}$ & $\begin{array}{c}0.34 \\
6224.59\end{array}$ \\
\hline
\end{tabular}

$$
S_{1}=\frac{(1 / 2) m_{1} v^{2} S_{0}+E_{0} S_{0}}{\lambda_{1} E_{0}-m_{1} g \sin \alpha \cdot S_{0}}
$$

where $\lambda_{1}=\left(k_{0} / k_{1}\right)$.

Equation (20) is deformed:

$$
\begin{aligned}
& \lambda_{1}=\frac{(1 / 2) m_{1} v^{2} S_{0}+E_{0} S_{0}+m_{1} g \sin \alpha \cdot S_{0} S_{1}}{S_{1} E_{0}}, \\
& E_{0}=\frac{0.5 m_{1} v^{2} S_{0}+m_{1} g \sin \alpha \cdot S_{0} \cdot S_{1}}{\lambda_{1} S_{1}-S_{0}} .
\end{aligned}
$$

4.2. Determination of Influence Coefficient and Analysis. For the calculation results of the ENKE of the test escalator in Section 3.4, it is actually assumed $\lambda_{1}=\left(k_{0} / k_{1}\right)=1$. According to this assumption, substitute the test results of the braking distance of Table 4 into equation (22); the ENKE calculation results of the three escalators can be obtained, as shown in Table 4.

Since the improved mathematical model thinks that the value of $\lambda_{1}$ is not 1 , the next step is to calculate the value of $\lambda_{1}$. Take escalator 1 as an example. Assuming that the $25 \%$ rated load is used as the reference, $\lambda_{1}=1$, so the ENKE at this time is $E_{0}=3353.0625 \mathrm{~J}$. Take $E_{0}=3353.0625 \mathrm{~J}$ as the ENKE of the system; that is to say, the ENKE of the system is a constant value $3353 \mathrm{~J}$ under any load (values after the decimal point are omitted). Then, the $\lambda_{1}$ value under different loads can be obtained from equation (21), as shown in Table 5 .

Similarly, for the escalator 2, substitute the test results of the braking distance in Table 4 into equation 22, and it can be calculated as $E_{0}=6059.34264$. The corresponding calculation results of $\lambda_{1}$ under different loads are shown in Table 6.

As can be seen in Table 6, the $25 \%$ rated load is used as the reference $\lambda_{1}=1$. When the load is 50\%, 75\%, and $100 \%$ rated load, the calculated $\lambda_{1}$ is $1.080,1.141$, and 1.239, respectively.

For the escalator 3, substitute the test results of the braking distance in Table 4 into equation (22), and it can be calculated as $E_{0}=4062.8403 \mathrm{~J}$. The corresponding calculation results of $\lambda_{1}$ under different loads are shown in Table 7.

It can be seen from Table 7 that when the load is $50 \%$, $75 \%$, and $100 \%$ rated load, the calculated $\lambda_{1}$ is $1.075,1.144$, and 1.234 , respectively.

This is approximately the same as the values of escalators 1 and 2 under the same load. Then, the comparison of the calculation results of the three escalators is shown in Figure 9 .

It can be intuitively seen from Figure 9 that the $\lambda_{1}$ value change trend of the three escalators under different loads is very consistent and basically coincides at a specific point. Therefore, it can be obtained that when the load is $25 \%$, $\lambda_{1} \approx 1$; when the load is $50 \%, \lambda_{1} \approx 1.08$; when the load is $75 \%, \lambda_{1} \approx 1.14$; when the load is $100 \%, \lambda_{1} \approx 1.234$, as shown in Table 8 .

The $\lambda_{1}$ value corresponding to the load not listed in Table 8 is calculated by the piecewise interpolation method.

The test results of the above three escalators show that, with the increase in load, $\lambda_{1}$ shows an increasing trend. But the growth rate decreases during the $50 \%-75 \%$ rated load stage, and the growth rate is faster at the $75 \%-100 \%$ rated load stage. The inflection point appears around $75 \%$ of the rated load. According to equation (20), as the load increases, the numerator becomes larger and the denominator becomes smaller. Due to the existence of $\lambda_{1}$, after $75 \%$ rated load, the speed at which the denominator becomes smaller is slowed down. This suppresses the excessively rapid increase in the braking distance, and a reasonable braking distance value is obtained.

So far, the improved braking distance prediction model of escalator has been completed, and the influence coefficient has been determined. To verify the improved mathematical model, the next section will test the model and compare it with the measured value.

\section{Test Results of Improved Model}

Since the determination of the parameters in the improved model is based on the three escalator tests mentioned in Sections 3.3 , the tilt angles are all $35^{\circ}$. In order to avoid interference, other three escalators with different models, different angles, and different rated loads were used as examples for testing. The parameters of the escalators are shown in Table 9.

The loading test process is shown in Figure 10.

The actual measurement results of the braking distance are shown in Table 10.

It can be seen from Table 10, for escalator 1, the braking distance with no load is small, and the increment between no-load and $25 \%$ rated load is small, so the braking distance increases slowly as the load increases, and the braking distance at rated load is also smaller, only $0.68 \mathrm{~m}$; for escalator 2, the no-load braking distance is larger, and the 
TABLE 5: Calculated result of $\lambda_{1}$ for escalator 1 .

\begin{tabular}{lcccc}
\hline Load percentage (\%) & 25 & 50 & 75 & 100 \\
\hline Equivalent no-load kinetic energy (J) & 3353 & 3353 & 3353 & 3353 \\
$\lambda_{1}$ & 1.000003924 & 1.08360672 & 1.135131174 & 1.227679976 \\
\hline
\end{tabular}

TABLE 6: Calculated result of $\lambda_{1}$ for escalator 2 .

\begin{tabular}{lcccc}
\hline Load percentage (\%) & 25 & 50 & 75 & 100 \\
\hline Equivalent no-load kinetic energy (J) & 6059 & 6059 & 6059 & 6059 \\
$\lambda_{1}$ & 1.000012852 & 1.080126793 & 1.141245873 & 1.239476107 \\
\hline
\end{tabular}

TABLe 7: Calculated result of $\lambda_{1}$ for escalator 3 .

\begin{tabular}{lcccc}
\hline Load percentage (\%) & 25 & 50 & 75 & 100 \\
\hline Equivalent no-load kinetic energy (J) & 4062 & 4062 & 4062 & 4062 \\
$\lambda_{1}$ & 1.000035977 & 1.075147415 & 1.144503496 & 1.234880806 \\
\hline
\end{tabular}

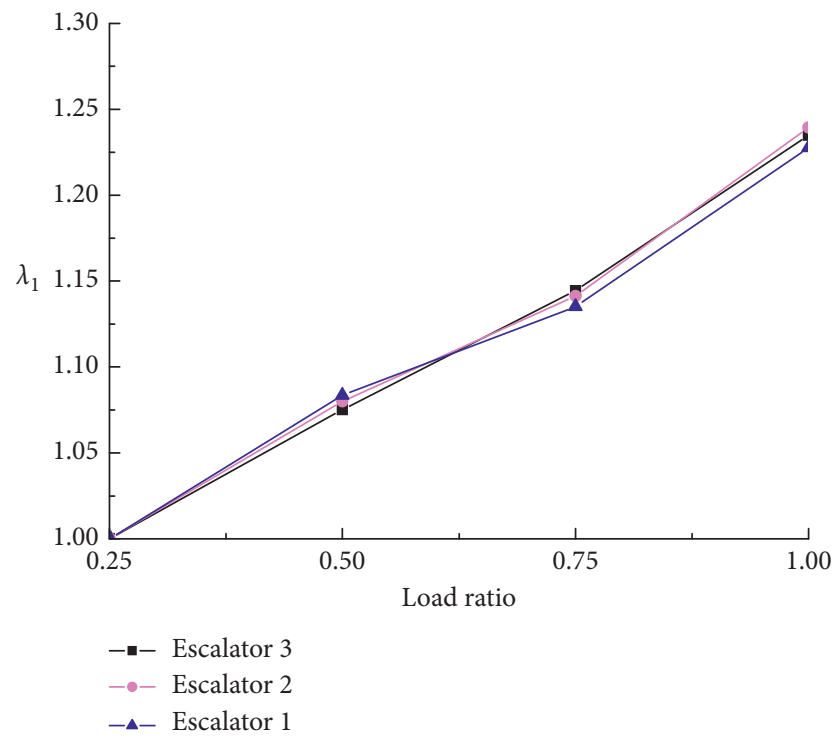

Figure 9: Comparison of $\lambda_{1}$ for three escalators.

TABLe 8: Values of $\lambda_{1}$.

\begin{tabular}{lcccc}
\hline Load percentage (\%) & 25 & 50 & 75 & 100 \\
\hline$\lambda_{1}$ & 1.000 & 1.080 & 1.140 & 1.234 \\
\hline
\end{tabular}

increase in the braking distance between no-load and 25\% rated load is larger, so with the increase in load, the braking distance increases rapidly. The braking distance at rated load is $1.09 \mathrm{~m}$, which has exceeded the standard requirements. Therefore, it can be concluded that, as the load increases, the braking distance shows an upward trend. When the braking distance change between no-load and 25\% rated load is greater, the braking distance increases faster and is likely to exceed the standard. On the contrary, the growth of the braking distance is relatively slow.
TABle 9: Parameters of tested escalators.

\begin{tabular}{lccc}
\hline Parameters & Escalator 1 & Escalator 2 & Escalator 3 \\
\hline Nominal speed & $0.5 \mathrm{~m} / \mathrm{s}$ & $0.5 \mathrm{~m} / \mathrm{s}$ & $0.5 \mathrm{~m} / \mathrm{s}$ \\
Tilt angle & $30^{\circ}$ & $35^{\circ}$ & $35^{\circ}$ \\
Lifting height & $3.6 \mathrm{~m}$ & $5.3 \mathrm{~m}$ & $5.0 \mathrm{~m}$ \\
Nominal width & $1000 \mathrm{~mm}$ & $1000 \mathrm{~mm}$ & $1000 \mathrm{~mm}$ \\
Rated load & $2000 \mathrm{~kg}$ & $2880 \mathrm{~kg}$ & $2640 \mathrm{~kg}$ \\
Power & $7.5 \mathrm{kw}$ & $11.0 \mathrm{kw}$ & $8.0 \mathrm{kw}$ \\
\hline
\end{tabular}

According to the back derivation method in Section 3.3, the actual measurement results of the no-load and 25\% rated load in Table 10 are substituted into equation (22). And the ENKE of each escalator is calculated under the current braking force, as shown in Table 11.

The ENKE of each escalator calculated in Table 11 is substituted into equation (20), and the predicted results of the braking distance under different loads of each escalator are calculated, as shown in Table 12 .

It can be seen from Table 12 that, for an escalator of $0.5 \mathrm{~m} /$ $\mathrm{s}$, when the braking distance with no load is close to $0.2 \mathrm{~m}$, the braking distance with rated load is predicted to be $0.67 \mathrm{~m}$. And there is space from the standard requirement of $1 \mathrm{~m}$; when the braking distance with no load exceeds $0.4 \mathrm{~m}$, the predicted value of the braking distance with rated load is basically close to the upper limit of the standard or even exceeds the standard. Relevant measures need to be taken to reduce the braking distance to ensure the safe of the escalator.

\section{Analysis and Discussion}

According to the test results in Section 5 above, the comparison between the predicted value of the improved braking distance prediction model and the measured value is shown in Figure 11.

By combining Tables 10 and 12 and Figure 11, it can be seen that the difference between the predicted value and the 


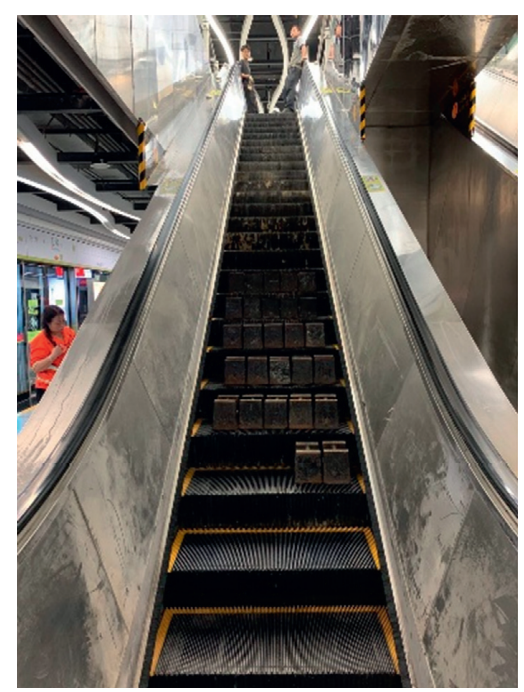

(a)

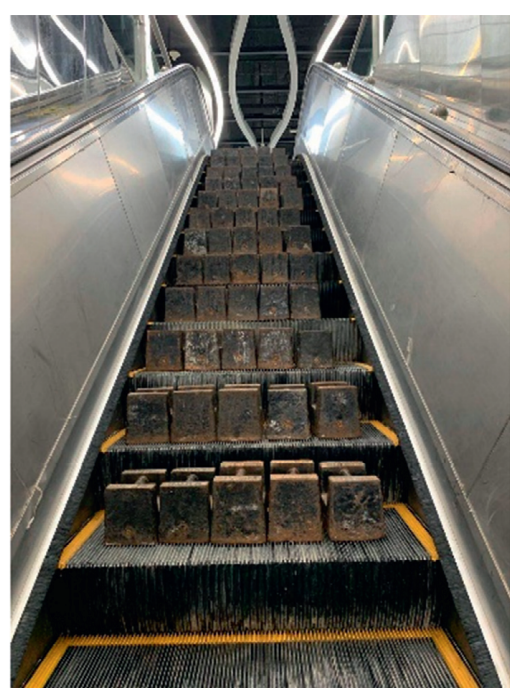

(b)

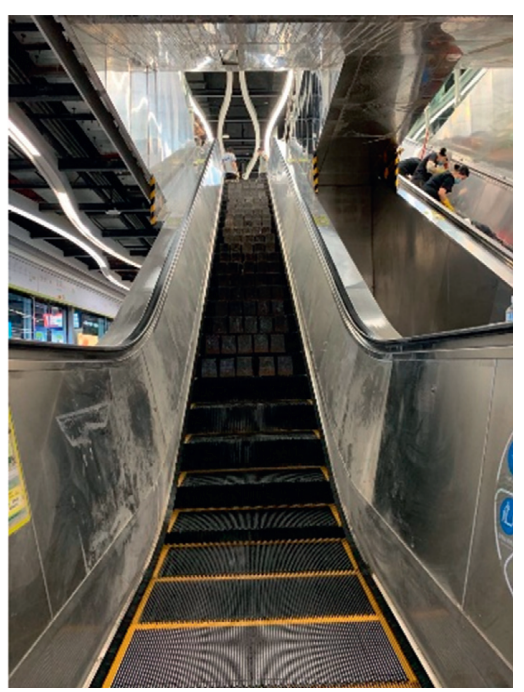

(c)

Figure 10: Load test of braking distance.

TABLe 10: Actual measurement results of braking distance.

\begin{tabular}{|c|c|c|c|c|c|}
\hline Load percentage (\%) & 0 & 25 & 50 & 75 & 100 \\
\hline Braking distance of escalator $1(\mathrm{~m})$ & 0.23 & 0.3 & 0.38 & 0.5 & 0.68 \\
\hline Braking distance of escalator $2(\mathrm{~m})$ & 0.45 & 0.57 & 0.7 & 0.88 & 1.09 \\
\hline Braking distance of escalator $3(\mathrm{~m})$ & 0.43 & 0.54 & 0.65 & 0.81 & 1.0 \\
\hline
\end{tabular}

TABLE 11: Calculated values of equivalent no-load kinetic energy.

\begin{tabular}{lccc}
\hline Escalator no. & Escalator 1 & Escalator 2 & Escalator 3 \\
\hline Equivalent no-load kinetic energy (J) & 2620.35 & 10441.08 & 9879.85 \\
\hline
\end{tabular}

TABle 12: Predicted value of braking distance for 3 escalators.

\begin{tabular}{|c|c|c|c|c|c|}
\hline Load percentage & 0 & $25 \%$ & $50 \%$ & $75 \%$ & $100 \%$ \\
\hline Predicted braking distance of escalator $1(\mathrm{~m})$ & 0.230 & 0.300 & 0.370 & 0.498 & 0.674 \\
\hline Predicted braking distance of escalator $2(\mathrm{~m})$ & 0.450 & 0.570 & 0.681 & 0.873 & 1.112 \\
\hline Predicted braking distance of escalator $3(\mathrm{~m})$ & 0.430 & 0.540 & 0.637 & 0.803 & 0.997 \\
\hline
\end{tabular}

measured value is $0.022 \mathrm{~m}$ at the maximum, and the maximum error is $2.7 \%$. It can meet the needs of engineering measurement. At the same time, the error we are more concerned about at $100 \%$ of the rated load is smaller, the minimum difference is only $0.003 \mathrm{~m}$, and the minimum error is $0.3 \%$. This means that the predicted value is closer to the actual value at $100 \%$ of the rated load.

It can be seen in Figure 11 that, before 50\% rated load, the slope of the curve of braking distance with load is smaller; after that, the slope of the curve of braking distance with load is larger, which means that, from $50 \%$ rated load, as the load increases, the braking distance increases faster. The analysis shows that, as the load increases, the kinetic energy of the escalator system continues to increase. At $50 \%$ rated load, on applying brake, due to the large impulse force, the critical point of friction is reached, causing the friction of the system to become sliding friction. The frictional force is reduced so that the braking distance increases more obviously.

Furthermore, in order to visually show the influence of the braking force on the braking distance, the braking force is adjusted on the escalator 1 . The braking force is increased first, and then, the braking force is reduced. The braking distance test method in Section 3.3 has been used for testing. The measured results of the braking distance before and after adjustment are shown in Table 13. 


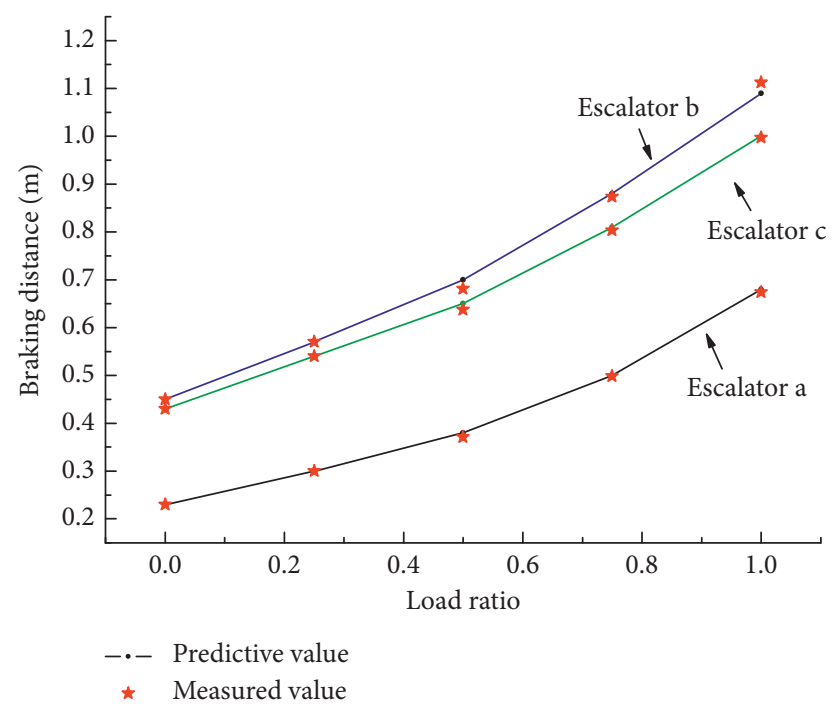

FIgURE 11: Measured and predicted values of three escalators.

TABLE 13: Test results before and after adjustment.

\begin{tabular}{lcccccc}
\hline Load percentage (\%) & 0 & 25 & 50 & 75 & 100 & Remarks \\
\hline Braking distance of escalator $(\mathrm{m})$ & 0.23 & 0.3 & 0.38 & 0.5 & 0.68 & Before adjustment \\
Braking distance of escalator $(\mathrm{m})$ & 0.18 & 0.24 & 0.32 & 0.43 & 0.62 & Increase the braking force \\
Braking distance of escalator $(\mathrm{m})$ & 0.26 & 0.34 & 0.42 & 0.6 & 0.8 & Decrease the braking force \\
\hline
\end{tabular}

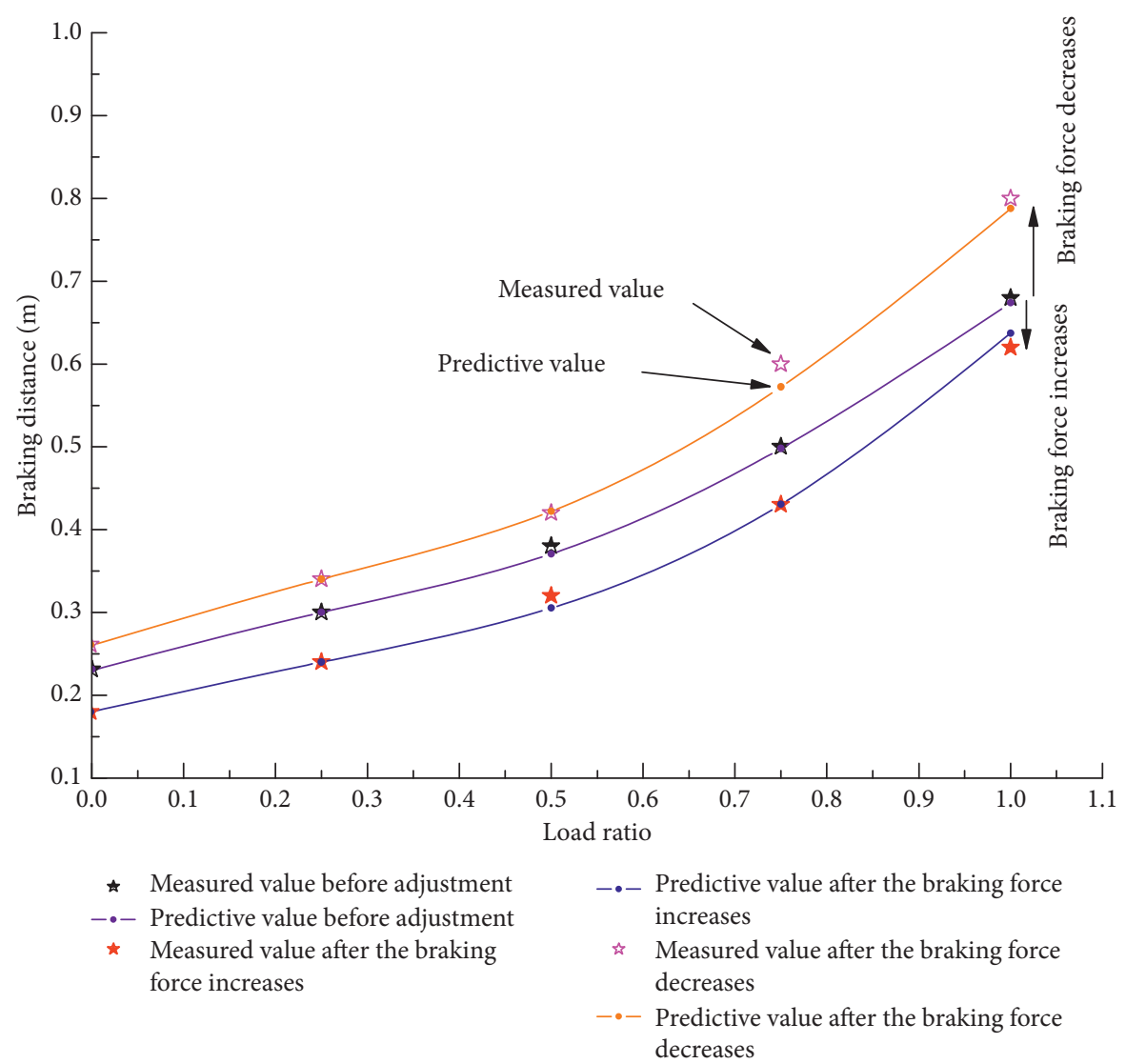

FIGURE 12: Comparison of braking distance before and after braking force adjustment. 
According to the back derivation method in Section 3.3, the actual measurement results of the no-load and $25 \%$ rated load in Table 13 are substituted into equation (22), respectively. The value of ENKE is calculated. And then, the predicted value of the braking distance can be obtained, respectively, according to equation (20) before and after adjustment. The comparison between the predicted value and the measured value is shown in Figure 12.

It can be seen from Figure 12 that the test value and the predicted value of the braking distance before and after the braking force adjustment are basically the same, indicating that the improved prediction model can meet the needs of engineering measurement. Before the braking force adjustment, the braking distance with no load is $0.23 \mathrm{~m}$. After the braking force increases, the braking distance with no load is $0.18 \mathrm{~m}$, indicating that the braking force will decrease when the braking force increases; after the braking force decreases, the braking distance with no load is $0.26 \mathrm{~m}$, indicating that the braking force will increase if the braking force decreases. The same phenomenon happened when rated loaded. Further analysis, from the braking distance test results of Table 13 and equation (22), the ENKE can be calculated to be $2620 \mathrm{~J}$, before the adjustment of the braking force. After the brake spring is tightened, that is, the braking force increases. Then, the result is that the braking distance becomes smaller. Correspondingly, from equation (22), the ENKE is $2223 \mathrm{~J}$, which also becomes smaller. After the brake spring is loosened, it means that the braking force is reduced. Then, the result is that the braking distance becomes larger. Correspondingly, from equation (22), the ENKE is $2910 \mathrm{~J}$, which also becomes larger. It can be concluded that the ENKE of an escalator with a large braking force is small; that is, the ENKE that needs to be consumed is small. In addition, the change in braking distance between no-load and 25\% rated load is large, indicating that the braking force is small, and the braking distance increases faster as the load increases.

\section{Conclusion}

In this paper, the relationship model between the braking distance and the load of the escalator is derived through the analysis of the force and energy changes in the escalator during braking. After experimental verification, it was found that the influence coefficients were inconsistent under noload and loaded conditions, and the model was revised accordingly, and an improved model was obtained. It realizes braking distance predicting various loads for escalator under light load test conditions, greatly reducing the safety hazards and test costs on traditional testing of braking distance under rated load and improving test efficiency:

(1) The prediction model before improvement considers that the influence coefficients are equal whether no load or loaded. However, it has been verified by experiments that the influence coefficient increases nonlinearly with the increase in the load. The improved prediction model revises the influence coefficient and proposes the change law of the influence coefficient on the braking distance. The results show that the maximum error between the braking distance predicted by the improved model and the braking distance measured by the loading method is $2.3 \%$, which meets the test error of engineering application.

(2) As the load increases, the braking distance is on the rise. When the difference of braking distance between no-load and $25 \%$ rated load is large, the braking distance increases faster and is likely to exceed the standard. On the contrary, the growth of the braking distance is relatively slow.

(3) The braking distance test is based on the power-off time, including the electrical and mechanical delay time of the brake. And the load influence coefficient is also obtained on this basis. If the braking distance test starts from braking, the load influence coefficient needs to be recalculated.

(4) The introduction of ENKE simplifies the model and ignores the influence of some intermediate quantities, which simplifies the calculation. At the same time, a back derivation method is proposed to calculate the ENKE, which avoids the complexity and uncertainty of the ENKE calculation.

(5) The improved prediction model shows that the escalator with a large braking force has a small ENKE; that is to say, for the braking force under this condition, the escalator is easy to stop. Conversely, the escalator with a small braking force has a large ENKE, so the escalator is not easy to stop, which is consistent with the actual situation.

\section{Data Availability}

The data used to support the findings of this study are available from the corresponding author upon request.

\section{Conflicts of Interest}

The authors declare that they have no conflicts of interest.

\section{Acknowledgments}

This research was funded by the Guangzhou Market Supervision Administration, China (no. 2020kj26), and Guangzhou Science and Technology Bureau, China (no. 202002030121).

\section{References}

[1] Guangdong Administration for Market Regulation, Notice of the Guangdong Administration for Maket Regulation on the Safety Status of Special Equipment in Guangdong Province in 2019 EB/OL, 2020. http://amr.gd.gov.cn/.

[2] S. Uimonen, T. Tukia, J. Ekstrom et al., "A machine learning approach to modelling escalator demand response," Engineering Applications of Artificial Intelligence, vol. 90, Article ID 103521, 2020. 
[3] Z. Zhou, Y. Zi, J. Chen et al., "Hazard analysis for escalator emergency braking system via system safety analysis method based on STAM," Applied Sciences, vol. 9, no. 21, Article ID 4530, 2019.

[4] K. Xie and Z. Liu, "Factors influencing escalator-related incidents in China: a systematic analysis using ism-dematel method," International Journal of Environmental Research and Public Health, vol. 16, no. 14, 2019.

[5] N. Rohatgi, K. Mehta, P. Sarkar, and T. C. Michael, "Emergency braking mechanism for an elevator using hydraulic and pneumatic actuation," International Journal of Reliability and Safety, vol. 13, no. 1-2, pp. 125-137, 2019.

[6] K. M. Mishra and K. Huhtala, "Elevator fault detection using profile extraction and deep autoencoder feature extraction for acceleration and magnetic signals," Applied Sciences, vol. 9, no. 15, p. 2990, 2019.

[7] Y. Xing, S. Dissanayake, J. Lu, S. Long, and Y. Lou, “An analysis of escalator-related injuries in metro stations in China, 2013-2015," Accident Analysis \& Prevention, vol. 122, pp. 332-341, 2019.

[8] Z. Chen and J. Xian, "Escalator-related injuries against preschoolers: an in-depth investigation in Guangdong province, China," Injury Prevention, vol. 22, no. 2, 2016.

[9] Z. Chen and J. Huang, "Escalator-related injuries against preschoolers: an in-depth investigation in Shanxi province, China," Injury Prevention, vol. 24, no. 2, 2018.

[10] A. Algin, U. Gulacti, M. O. Erdogan, I. Tayfur, K. Yusufoglu, and U. Lok, "Escalator-related injuries in one of the deepest subway stations in Europe," Annals of Saudi Medicine, vol. 39, no. 2, pp. 112-117, 2019.

[11] S. S. M. Gob, S. L. Chong, and A. Tyebally, "Danger in shopping centres-a study on escalator-related injuries in children in Singapore," Annals Academy of Medicine Singapore, vol. 47, no. 8, pp. 353-356, 2018.

[12] Q. Peng, Z. Li, H. Yuan, G. Huang, S. Li, and X. Sun, "A model-based unloaded test method for analysis of braking capacity of elevator brake," Advances in Materials Science and Engineering, vol. 2018, Article ID 8047490, 10 pages, 2018.

[13] Y. Xing, S. Chen, S. Zhu et al., "Analysis factors that influence escalator-related injuries in metro stations based on bayesian networks: a case study in China," International Journal of Environmental Research and Public Health, vol. 17, no. 2, p. 481, 2020.

[14] Q. Peng, A. Jiang, H. Yuan, G. Huang, S. He, and S. Li, “Study on theoretical model and test method of vertical vibration of elevator traction system," Mathematical Problems in Engineering, vol. 2020, Article ID 8518024, 12 pages, 2020.

[15] J. Sun, M. Yuan, and Z. Lin, "Classification and risk prevention of escalator accidents-A study on risk prevention and evaluation of escalator accidents in escalator," Journal of Beijing Vocational College of Politics and Law, vol. 2, pp. 100-105, 2017.

[16] S. M. Kalikate, S. R. Patil, and S. M. Sawant, "Simulationbased estimation of an automotive magnetorheological brake system performance," Journal of Advanced Research, vol. 14, pp. 43-51, 2018.

[17] E. Durak and H. A. Yurtseven, "Experimental study of the tribological properties of an elevator's brake linings," Industrial Lubrication and Tribology, vol. 68, no. 6, pp. 683-688, 2016.

[18] H. Lü, Z. Cai, Q. Feng, W.-B. Shangguan, and D. Yu, “An improved method for fuzzy-interval uncertainty analysis and its application in brake instability study," Computer Methods in Applied Mechanics and Engineering, vol. 342, pp. 142-160, 2018.

[19] Z. Wang, L. Qin, and S. Xiuya, "Analysis of power supply immunity based on heavy-duty escalator brakes," China Elevator, vol. 15, no. 30, pp. 9-12, 2019.

[20] J. Bao, Z. Li, and D. Hu, "Frictional performance and temperature rise of a mining nonasbestos brake material during emergency braking," Advances in Materials Science and Engineering, vol. 2015, Article ID 867549, 7 pages, 2015.

[21] C. J. Park and G. Gschwendtner, "Braking performance analysis of an escalator system using multibody dynamics simulation technology," Journal of Mechanical Science and Technology, vol. 29, no. 7, pp. 2645-2651, 2015.

[22] G. Pan and L. Chen, "Impact analysis of brake pad backplate structure and friction lining material on disc-brake noise," Advances in Materials Science and Engineering, vol. 2018, Article ID 7093978, 9 pages, 2018.

[23] General Administration of Quality Supervision, Inspection and Quarantine Code for Elevator Supervision, Inspection and Periodic Inspection-Escalators and Moving walkwayS: TSG T 7005-2012, General Administration of Quality Supervision, Beijing, China, 2012.

[24] W. Wang and J. Lu, "Calculation of braking capacity of escalators and travelator," Mechanical Design, no. 5, pp. 18-19, 2006.

[25] X. Pan, "The stopping distance of escalators," China Special Equipment Safety, vol. 32, no. 10, pp. 27-29, 2012.

[26] A. Hu, "A brief talk on a new method to establish a mathematical model of escalator braking distance," Electromechanical Information, no. 24, pp. 51-52, 2014.

[27] Z. Liu, "A brief talk on calculation of braking distance of escalator and travelator. Modern manufacturing technology and equipment," Lack of Roll, no. 5, pp. 63-64, 2019.

[28] L. Pu, G. Chen, and L. Wu, Mechanical Design, Higher Education Press, Beijing, China, 2019. 